Central European Journal of Energetic Materials, 2016, 13(1), 33-52

ISSN 1733-7178

e-ISSN 2353-1843

\title{
MTX-1 - A Potential Replacement for Tetrazene in Primers
}

John W. FRONABARGER ${ }^{1}$, Michael D. WILLIAMS ${ }^{1, *}$, Alfred G. STERN ${ }^{2}$, Damon A. PARRISH ${ }^{3}$

${ }^{1}$ Pacific Scientific Energetic Materials Co., 7073 W. Willis Rd., Chandler, AZ 85226, USA

${ }^{2}$ Naval Surface Warfare Center, Indian Head Explosive Ordnance Disposal Technology Division (NSWC IHEODTD), Code TD5, 4104 Evans Way, Indian Head, MD 20640-5102, USA

${ }^{3}$ Naval Research Laboratory, Code 6910, 4555 Overlook Ave., Washington, D.C. 20375, USA

*E-mail: mwilliams@psemc.com

\begin{abstract}
Tetrazene (1-amino-1(1H-tetrazol-5-yl)-azo-guanidine hydrate) is widely used in ordnance systems as a sensitizer of primer mixes for use in both percussion and stab applications. It has low thermal and hydrolytic stability compared with other components of primer mixes and there currently exists the need for a replacement with enhanced stability characteristics. MTX-1 (1-[(2E)3-(1H-tetrazol-5-yl)triaz-2-en-1-ylidene]methanediamine) meets these criteria and shows great promise as a tetrazene replacement. Preliminary testing of this material has confirmed that MTX-1 has safety and performance properties which are similar to tetrazene and has chemical characteristics, including thermal and hydrolytic stability, which exceed those of tetrazene. MTX-1 has been successfully evaluated against tetrazene in a variety of chemical/output tests, including comparative testing in the PVU-12 primer.
\end{abstract}

Keywords: MTX-1, tetrazene, sensitizer, primer 


\section{Introduction}

Tetrazene (1, Figure 1 below, CAS \#109-27-3, MIL-T-46938) is widely used in ordnance systems as a sensitizer of primer mixes for use in both percussion and stab applications. It has low thermal and hydrolytic stability compared with other components of primer mixes and there currently exists the need for a replacement with enhanced stability characteristics.

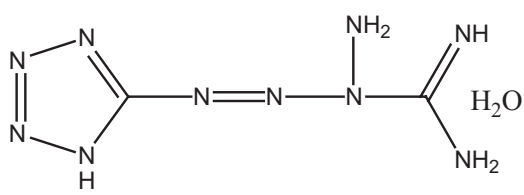

Figure 1. Structure of tetrazene.

This material was initially prepared in 1910 by Roth and Hoffman [1] and the structure was elucidated as shown by Duke [2]. While other structures have been suggested in the literature, this structure was recently confirmed via x-ray analysis by Klapötke's group (per. comm., 2010). Tetrazene first found use in primer compositions in Germany in the 1920s due primarily to the work of Von Herz who demonstrated it to be non-corrosive as well as free of the toxic mercury fulminate used up to that point. In the US, mercury fulminate based primers were initially replaced with FA70 [3] which contained potassium chlorate, lead thiocyanate and TNT. These compositions, although useful for high temperature applications, also proved corrosive and were replaced, in 1948, by FA956 containing tetrazene and lead styphnate and developed by Rathsburg.

Current percussion primer mixes, such as FA956 [4], PA101 [4], VH2 [5], L Mix [5], PA100 [3], and numerous others contain tetrazene in varying amounts (2-5\%). A typical composition would be FA956, containing normal lead styphnate $37 \%$, barium nitrate(V) $32 \%$, antimony sulfide $15 \%$, aluminium powder $7 \%$, PETN 5\% and tetrazene $4 \%$. Stab compositions are similar, however they contain lead azide. For example NOL-130 [3] contains basic lead styphnate $40 \%$, lead azide $20 \%$, barium nitrate(V) $20 \%$, antimony sulfide $15 \%$ and tetrazene $5 \%$. The NOL-130 composition is relatively insensitive to stab initiation when the tetrazene component is omitted. The addition of $\geq 2 \%$ tetrazene is currently a requirement to ensure high stab sensitivity. It has been proposed that the low mechanical energy required for initiation of tetrazene based compositions is a direct result of its low temperature of ignition [5] $\left(143{ }^{\circ} \mathrm{C}\right)$, in conjunction with its metastable chemical structure. This may be related to the mechanism of initiation, where mechanical energy is applied to the primer and 
that energy is converted to heat by friction and/or impact events between the explosive materials and/or grits in the composition [6].

Spear and Elischer [7a] have investigated a number of compounds as alternatives to tetrazene for sensitizing lead azide, and found some correlation between ignition temperature and initiation energies. These materials, which included free acids and metal salts of tetrazolates and dinitrophenolates, demonstrated optimum sensitization if they were hard crystalline solids with low ignition temperatures and high friction coefficients, corresponding to the "hot spot" concept of initiation.

Tetrazene suffers from a number of issues, most importantly low thermal and hydrolytic stabilities. It has been demonstrated that tetrazene readily decomposes at $\sim 90{ }^{\circ} \mathrm{C}$, which may be in the temperature range encountered during use. Bird [8] has demonstrated, using IR and UV monitoring, that at $90^{\circ} \mathrm{C}$, one mole of tetrazene decomposes to afford 1.7 mole of 5-aminotetrazole (2, Figure 2) via a fragmentation process, followed by cyclization of a majority of the guanyl azide decomposition product.

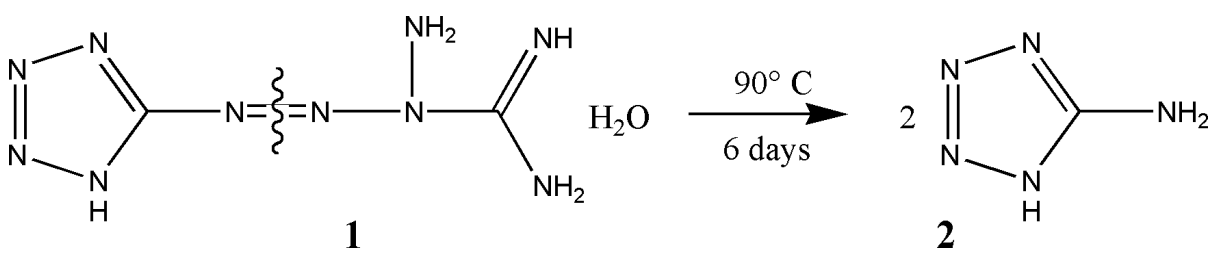

Figure 2. Thermal decomposition of tetrazene.

This decomposition is complete after one week at $90{ }^{\circ} \mathrm{C}$ and appears to be auto-catalytic; therefore it may be reasonable to presume that it will occur to some extent at lower temperatures. More recent investigations [9], including work done for this publication have confirmed these results. Tetrazene has also been shown to be susceptible to hydrolytic decomposition [7b] and is destroyed/ decomposed simply by addition to boiling water or by extended suspension in water at ambient temperature.

As a result, it is clear that there is a need to develop stab or percussion sensitive materials with improved thermal stability for primers used in normal or high temperature applications. In light of current environmental concerns, it would also be beneficial to generate this new material both cheaply and without the use of toxic materials as reactants or effluents.

Pacific Scientific EMC has been involved in a program, in conjunction with NSWC-IHEODTD, to develop replacements for both lead azide (LA) and lead styphnate (LS) which do not contain toxic or environmentally objectionable 
metals [10]. One series of lead azide candidates resulting from this study were salts and complexes of ditetrazolyltriazene (DTET). Comparison of the chemical structures of tetrazene and DTET reveals that the materials are structurally similar, i.e., tetrazene possesses an aminoguanidine group that has been exchanged with an aminotetrazole in DTET. However, it was found that DTET forms hydrates and therefore its salts and complexes are expected to be hygroscopic, which would result in desensitization.

An alternative to DTET is shown below (3, Figure 3) and was initially considered to be a cyclized tetrazene derivative or "iso-DTET" containing six contiguous nitrogen atoms [11]. Iso-DTET would be considered a sensitizing molecule based on it similarities to not only DTET and tetrazene, but also to 1,5-diaminotetrazole. Subsequent chemical and X-ray studies have indicated that the material is actually 4, designated MTX-1 [12] (CAS \#1281861-76-4). It is conveniently prepare from tetrazene in one step, in aqueous solution.

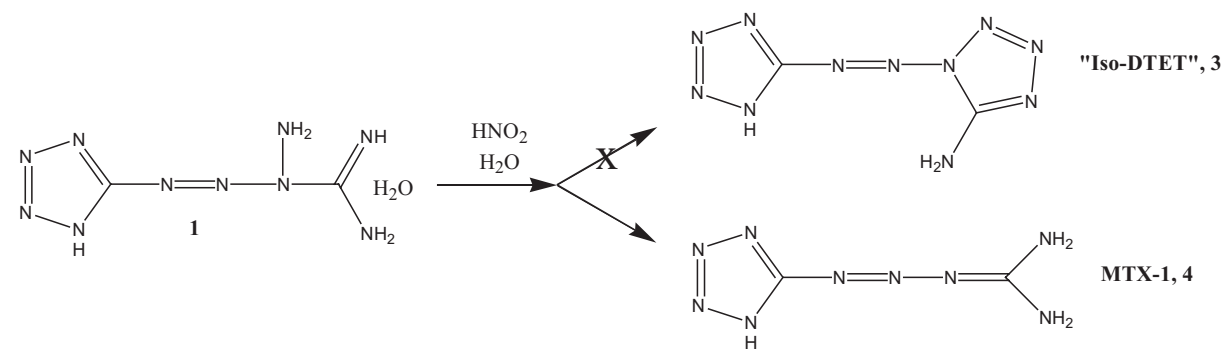

Figure 3. Synthesis of MTX-1.

MTX-1 is presumably formed via a 2-step elimination of nitrous oxide from the labile N-nitrosamine intermediate [13] generated by the reaction of nitrous acid on the $\mathrm{N}$-amino group of $\mathbf{1}$ as shown in Figure 4.

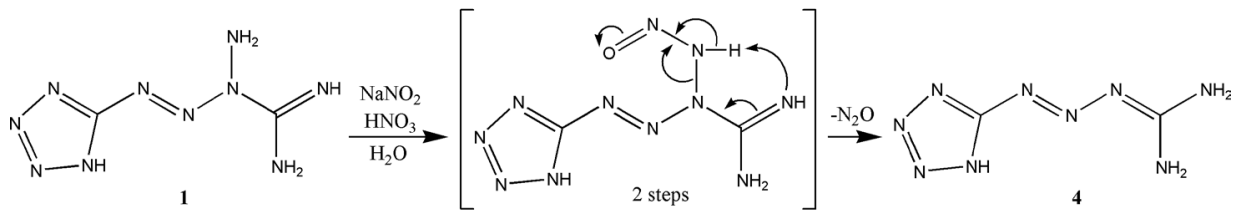

Figure 4. Mechanism of MTX-1 formation. 


\section{Materials and Methods}

Tetrazene is used as a reactant in the preparation of MTX-1 and may be easily produced from either aminoguanidine nitrate [14] (AGN) or aminoguanidine bicarbonate [15] (AGB). Although AGN is a more costly starting material, it gave small needles and was demonstrated to be a useful starting material for (small particle) MTX-1. However, synthesis from AGB is substantially more cost effective, is higher yielding with equivalent or better purity than AGN based MTX-1, and affords tetrazene that often appears as large needles which have approximately twice the aspect ratio of those produced by the nitrate method.

Utilizing the procedure below, laboratory quantities of MTX-1 may be prepared reproducibly in $60-80 \%$ overall yield. The benefits of this reaction sequence include a low volume, aqueous reaction system producing only minor amounts of effluent and utilizing low- or non-toxic reactants. The MTX-1 forms as a crystalline white or tan solid and may separate in either a needle or granular morphology. Extended experimental evidence suggests that MTX-1 samples prepared at ambient temperature generally form as needles with a morphology similar to tetrazene, while samples prepared at higher temperature have a much smaller and more granular appearance and are more prone to agglomeration. Further experiments directed towards consistent control of the morphology are planned.

\subsection{MTX-1 laboratory synthesis procedure}

A solution of $\mathrm{NaNO}_{2}(1.22 \mathrm{~g}, 1.50$ eq. $)$ in water $(\sim 10 \mathrm{~mL})$ was added over $\sim 10 \mathrm{~min}$, at a constant rate to maintain a temperature of $25^{\circ} \mathrm{C}$, to a stirred suspension of tetrazene $(2.00 \mathrm{~g}, 11.76 \mathrm{mmol})$ in $1 \mathrm{~N}$ aq. $\mathrm{HNO}_{3}(\sim 100 \mathrm{~mL})$. The mixture was stirred at ambient temperature for $4.0 \mathrm{~h}$ during which time the initial wheat coloured suspension turned white. The white MTX-1, 4, was filtered off, was washed with water (3-4 times), and dried in a convection oven at $65^{\circ} \mathrm{C}$ for 2 hours to give 1.3-1.5 g ( 70\%) of white crystals: DSC $215^{\circ} \mathrm{C}$ (dec.) ( $\mathrm{T}_{\text {peak }}$, $20^{\circ} \mathrm{C} \cdot \mathrm{min}^{-1}$ ); IR (ATR, $\left.\mathrm{cm}^{-1}\right) v=3323$ (vs), 3154 (s), 1700 (vs), 1675 (vs), 1583 (m), 1552 (m), 1457 (m), 1350 (m), 1242 (vs), 1183 (s), 1118 (s), 1032 (m), 831 (w), $750(\mathrm{w}), 507(\mathrm{w}), 488(\mathrm{w})$.

Caution! MTX-1 is a primary explosive with increased sensitivity to a variety of stimuli. Proper protective measures (safety glasses, face shield, Nomex lab coat, leather or Kevlar gloves and grounded equipment and shoes) should be used when working with this material, particularly when working on a gram scale. 


\section{Results and Discussion}

\subsection{Structural analysis}

For the purposes of structure elucidation, various attempts were made to crystallize an appropriate salt of MTX-1 to form suitable crystals for single crystal $\mathrm{X}$-ray studies. The preparation of a series of salts, including $\mathrm{Cu}(\mathrm{II}), \mathrm{Fe}(\mathrm{II})$ and $\mathrm{Fe}(\mathrm{III})$, and $\mathrm{Mn}(\mathrm{II})$, at elevated temperature in aqueous solution were unsuccessful and afforded only starting material. The reaction of the quantitatively formed potassium salt of MTX-1 with $\mathrm{CsOH}, \mathrm{RbOH}$ or tetraphenylphosphonium chloride gave highly crystalline materials in aqueous solution. The results of single crystal $\mathrm{X}$-ray analysis for the cesium salt are shown below in Table 1 and Figure 5. Collection data for the X-ray analysis follows: $\mathrm{C}_{2} \mathrm{H}_{6} \mathrm{CsN}_{9} \mathrm{O}, \mathrm{FW}=305.07$, Orthorhombic, $\mathrm{P} 2{ }_{1} 22_{1}, \mathrm{a}=6.9319(6) \AA, \mathrm{b}=9.2247(8) \AA, \mathrm{c}=13.4779(12) \AA$, $\alpha=90^{\circ}, \beta=90^{\circ}, \gamma=90^{\circ}, \mathrm{V}=861.84(13) \AA^{3}, \mathrm{Z}=4, r_{\text {calc }}=2.351 \mathrm{Mg} / \mathrm{m}^{3}$, $\mu=4.277 \mathrm{~mm}^{-1}, F(000)=576, \mathrm{R}_{1}=0.0147$ for 2145 observed (I $\left.>2 \sigma \mathrm{I}\right)$ reflections and 0.0150 for all 2166 reflections, Goodness-of-fit $=1.042,125$ parameters.

A yellow prism of dimensions $0.43 \times 0.41 \times 0.38 \mathrm{~mm}^{3}$ was mounted on a MiteGen MicroMesh using a small amount of Cargille Immersion Oil. Data were collected on a Bruker three-circle platform diffractometer equipped with a SMART APEX II CCD detector. The crystals were irradiated using graphite monochromated $\mathrm{MoK}_{\alpha}$ radiation $(\lambda=0.71073)$. An Oxford Cobra low temperature device was used to keep the crystals at a constant $296 \pm 2 \mathrm{~K}$ during data collection.

Data collection was performed and the unit cell was initially refined using APEX2 [v2010.3-0] [16]. Data Reduction was performed using SAINT [v7.68A] [17] and XPREP [v2008/2] [18]. Corrections were applied for Lorentz, polarization, and absorption effects using $S A D A B S$ [v2008/1] [19]. The structure was solved and refined with the aid of the programs in the SHELXTL-plus [v2008/4] system of programs [20]. The full-matrix least-squares refinement on $\mathrm{F}^{2}$ included atomic coordinates and anisotropic thermal parameters for all non- $\mathrm{H}$ atoms. The $\mathrm{H}$ atoms were included using a riding model. The crystal was a two-component merohedral twin and was refined as such. The relative populations of the two components are approximately 60:40.

Other relevant data and parameters of the X-ray measurements are given in Table 1 and the molecular unit showing the atom-labelling scheme is shown in Figure 5. Additional information on the crystal structure determination including atomic coordinates, bond lengths and angles and torsion angles is available from the authors. 
Table 1. Crystal data and structure refinement for MTX-1 (Cs salt)

\begin{tabular}{|c|c|c|}
\hline Identification code & PSC007 (EL3R152A) & \\
\hline Empirical formula & $\mathrm{C}_{2} \mathrm{H}_{6} \mathrm{~N}_{9} \mathrm{OCs}$ & \\
\hline Formula weight & 305.07 & \\
\hline Temperature & $296 \mathrm{~K}$ & \\
\hline Wavelength & $0.71073 \AA$ & \\
\hline Crystal system & Orthorhombic & \\
\hline Space group & $\mathrm{P} 2_{1} 2_{1} 2_{1}$ & \\
\hline \multirow{3}{*}{ Unit cell dimensions } & $a=6.9319(6) \AA$ & $\alpha=90^{\circ}$ \\
\hline & $\mathrm{b}=9.2247(8) \AA$ & $\beta=90^{\circ}$ \\
\hline & $\mathrm{c}=13.4779(12) \AA$ & $\gamma=90^{\circ}$ \\
\hline Volume & $861.84(13) \AA^{3}$ & \\
\hline $\mathrm{Z}$ & 4 & \\
\hline Density (calculated) & $2.351 \mathrm{Mg} / \mathrm{m}^{3}$ & \\
\hline Absorption coefficient & $4.277 \mathrm{~mm}^{-1}$ & \\
\hline $\mathrm{F}(000)$ & 576 & \\
\hline Crystal size & $0.43 \times 0.41 \times 0.38 \mathrm{~mm}^{3}$ & \\
\hline Theta range for data collection & 2.68 to $28.39^{\circ}$ & \\
\hline Index ranges & $\begin{array}{l}-9<=\mathrm{h}<=9,-12<=\mathrm{k}<=12 \\
-18<=\mathrm{k}<=18\end{array}$ & \\
\hline Reflections collected & 9117 & \\
\hline Independent reflections & $2166\left[\mathrm{R}_{\text {int }}=0.0180\right]$ & \\
\hline Completeness to theta $=28.39^{\circ}$ & $99.9 \%$ & \\
\hline Absorption correction & $\begin{array}{l}\text { Semi-empirical from } \\
\text { equivalents }\end{array}$ & \\
\hline Max. and min. transmission & 0.2933 and 0.2606 & \\
\hline Refinement method & $\begin{array}{l}\text { Full-matrix least-squares } \\
\text { on } \mathrm{F}^{2}\end{array}$ & \\
\hline Data / restraints / parameters & $2166 / 0 / 125$ & \\
\hline Goodness-of-fit on $\mathrm{F}^{2}$ & 1.042 & \\
\hline Final R indices [I>2 sigma(I)] & $\mathrm{R}_{1}=0.0147, \mathrm{wR}_{2}=0.0359$ & \\
\hline $\mathrm{R}$ indices (all data) & $\mathrm{R}_{1}=0.0150, \mathrm{wR}_{2}=0.0361$ & \\
\hline Largest diff. peak and hole & 0.188 and -0.502 e. $\AA^{-3}$ & \\
\hline
\end{tabular}




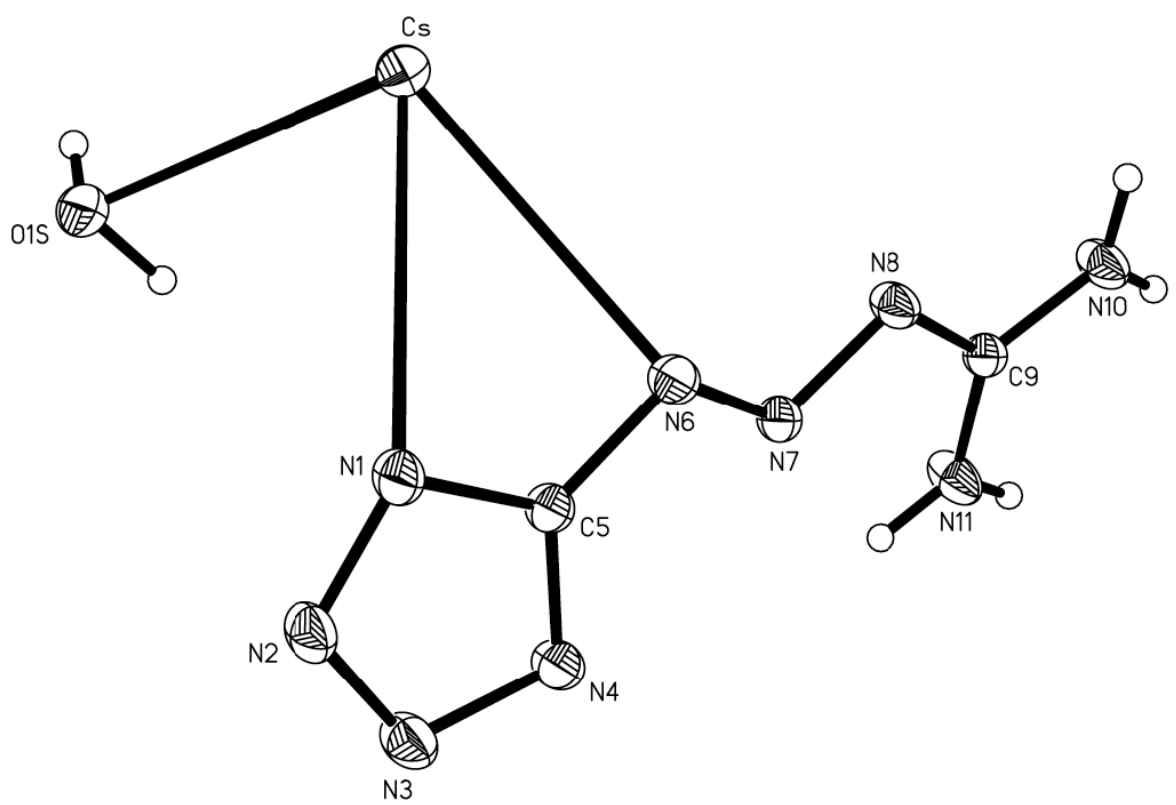

Figure 5. Molecular unit of MTX-1 (Cs salt). Thermal ellipsoids represent $50 \%$ probability.

\subsection{Thermal analysis}

DSC measurements for determining the thermal behaviour of both MTX-1 and tetrazene were performed in sealed aluminum cups on a TA Instruments Q2000 instrument. The DSC plot in Figure 6 demonstrates typical thermal behaviour of 0.12-0.13 mg of MTX-1 and tetrazene in the temperature range $50{ }^{\circ} \mathrm{C}$ to $300{ }^{\circ} \mathrm{C}$ (hermetic aluminum pan) at a heating rate of $20^{\circ} \mathrm{C} \cdot \mathrm{min}^{-1}$. 


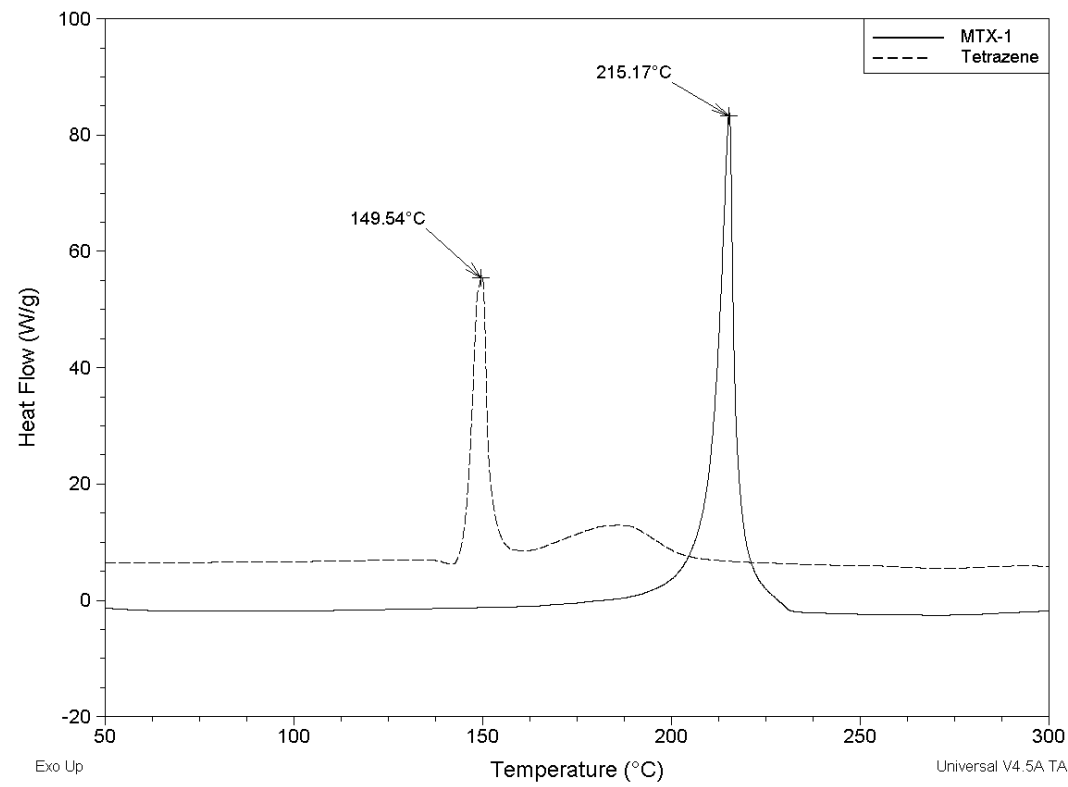

Figure 6. DSC plot of MTX-1 and tetrazene at $20{ }^{\circ} \mathrm{C} \mathrm{min}-1$.

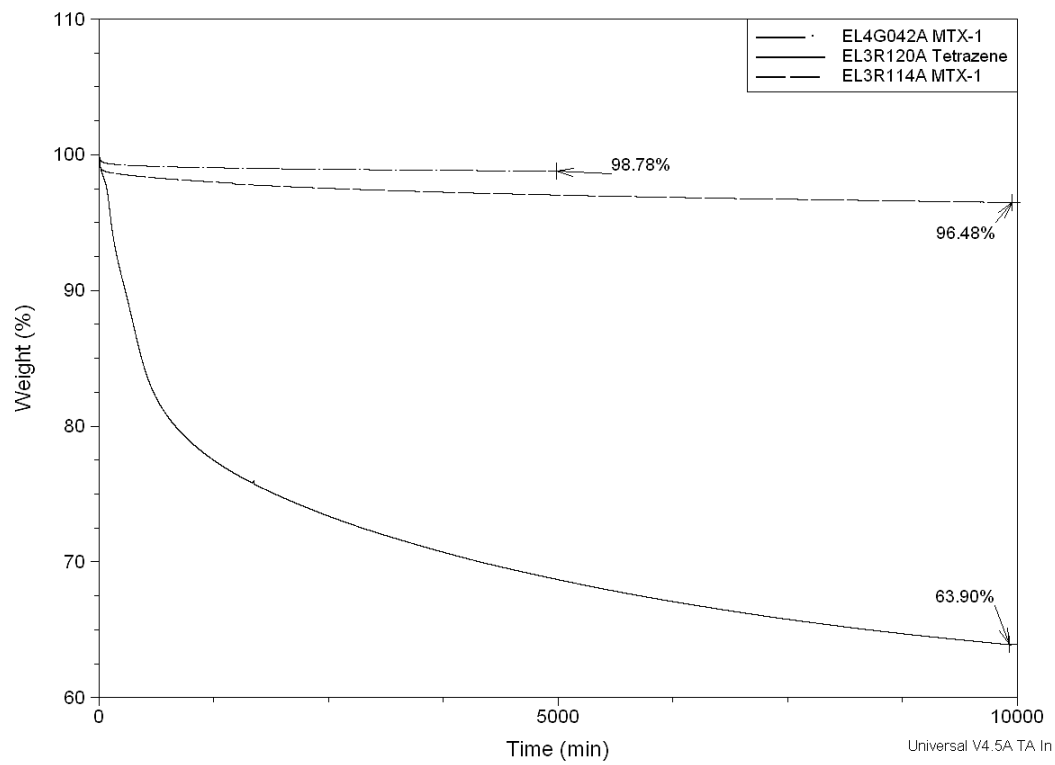

Figure 7. TGA comparison of tetrazene and MTX-1 samples at $90^{\circ} \mathrm{C}$. 
The thermal stabilities of MTX-1 (and tetrazene for comparison) were evaluated by TGA (TA Instruments 2950 thermogravimetric analyzer, alumina pans) as shown in Figure 7 below. In these experiments, samples were heated to $90{ }^{\circ} \mathrm{C}$ and then held at $90{ }^{\circ} \mathrm{C}$ for an extended period to evaluate the stability at that temperature. Tetrazene was run for $10000 \mathrm{~min}(167 \mathrm{~h})$ and lost $36 \%$ by weight over that period, with the majority of the weight loss occurring rapidly in the initial $1000 \mathrm{~min}$. FTIR analysis of the TGA residue indicated exclusively 5-aminotetrazole, confirming Bird's [8] fragmentation hypothesis. MTX-1was exposed to identical conditions for $18000 \mathrm{~min}(300 \mathrm{~h})$ and lost only $3.5 \%$ by weight, slowly over that time. Based on this observation, additional experiments on other MTX-1 samples were performed for $5000 \mathrm{~min}$ and, for these samples, the weight loss was less (see Figure 7) even if extrapolated to $18000 \mathrm{~min}$. These experiments would appear to indicate that MTX-1 has vastly superior thermal stability compared to tetrazene.

\subsection{Physical/chemical properties}

\subsubsection{Bomb calorimetry}

Calorimetric measurements were made on MTX-1 samples utilizing a Parr 6200 bomb calorimeter equipped with either a Parr 1104 or 1108 oxygen bomb.

Heat of Explosion (MTX-1): 2253.8 J/g (Ar)

Heat of Explosion (Tetrazene): $2754.9 \mathrm{~J} / \mathrm{g}(\mathrm{Ar})$

The values are in excellent agreement with the literature value $(2754.4 \mathrm{~J} / \mathrm{g})$ for tetrazene [21] and in good agreement with the values determined from DSC experiments used in determining the critical temperature (below).

The heat of combustion for a variety of MTX-1 samples was also determined using a Parr 6200 bomb calorimeter/1108 oxygen bomb. Interestingly, the bomb residue was a red gum. It is conceivable that this material may be a tetrazine derivative which is plausible via recombination of a guanyl azide type decomposition product. A correction for the nitric acid formed was determined via titration of the bomb residues with standardized base. The average value is given below.

Heat of Combustion (MTX-1): $12164.7 \mathrm{~J} / \mathrm{g}\left(\mathrm{O}_{2}\right)$

$\mathrm{DU}=0.3047-0.3245^{\circ} \mathrm{C}, 0.250-0.265 \mathrm{~g}$ sample weight ( 9 samples $)$

The heat of formation was determined from the average heat of combustion 
value via:

$\Delta \mathrm{H}^{\circ}=\Sigma\left(v \times \Delta \mathrm{H}_{\mathrm{f}}^{\circ}\right)\left(\right.$ products, $\left.\mathrm{CO}_{2} / \mathrm{N}_{2} / \mathrm{H}_{2} \mathrm{O}\right)-\Sigma\left(v \times \Delta \mathrm{H}_{\mathrm{f}}^{\circ}\right)\left(\right.$ reactants, MTX-1, $\left.\mathrm{O}_{2}\right)$

Heat of Formation $\left(\Delta \mathrm{H}_{\mathrm{f}} \mathrm{MTX}-1\right): 382.6 \mathrm{~kJ} / \mathrm{mol}$

Heat of Formation $\left(\Delta \mathrm{H}_{\mathrm{f}}\right.$ Tetrazene [22]): $212.5 \mathrm{~kJ} / \mathrm{mol}$

\subsubsection{Critical temperature}

The densities of both tetrazene and MTX-1 samples were measured by He pycnometry (Micromeritics AccuPyc 1330) and were $1.68 \mathrm{Mg} / \mathrm{m}^{3}$ and $1.64 \mathrm{Mg} / \mathrm{m}^{3}$, respectively. The densities were used in conjunction with the DSC rate experiments to estimate the critical temperatures for both tetrazene and MTX-1 using MIL-STD-1751A Method 1074. The DSC rate experiments for tetrazene and MTX-1 allowed the determination of the activation energy, preexponential (frequency factor) and heat of decomposition for both materials. The specific heat capacities of the materials were measured directly using modulated DSC in the temperature range of interest per ASTM E1269 [23]. The thermal conductivities for tetrazene and MTX-1 were estimated per MIL-STD-1751A, method 1074 [24]. The activation energy was determined from Kissinger plots [25] for tetrazene and MTX-1; the Kissinger plot for tetrazene contains two curves due to the complex nature of tetrazene decomposition [26] and results in a range for the pre-exponential and thus the critical temperature. The critical temperatures for the materials of interest were then calculated using the FrankKamenetskii equation [27].

Pre-exponential (MTX-1): $7.72 \times 10^{21} 1 / \mathrm{S}$

Pre-exponential (tetrazene): $2.69 \times 10^{21}$ to $3.99 \times 10^{20} 1 / \mathrm{S}$

$\mathrm{E}_{\mathrm{a}}(\mathrm{MTX}-1)=218 \mathrm{~kJ} / \mathrm{mol}$

$\mathrm{E}_{\mathrm{a}}($ Tetrazene $)=179.5-182 \mathrm{~kJ} / \mathrm{mol}$

$\mathrm{T}_{\mathrm{c}}=155-176{ }^{\circ} \mathrm{C}($ MTX-1), $1.0 \mathrm{~cm}$ diameter sphere at 80\% TMD.

$\mathrm{T}_{\mathrm{c}}=94-114{ }^{\circ} \mathrm{C}$ (Tetrazene), $1.0 \mathrm{~cm}$ diameter sphere at $80 \% \mathrm{TMD}$.

\subsubsection{Association constant $\left(K_{a}\right)$ for $M T X-1$}

The low solubility of MTX-1 prohibits determination of the $\mathrm{K}_{\mathrm{a}}$ by the HendersonHasselback method, since the anion/acid ratio cannot be determined due to the insolubility of the acid form. An alternate method, based on that reported by Ramette [28] was chosen and is based on a specific experiment done for bromcresol green. In the case of MTX-1, three solutions were prepared from a water saturated solution of MTX-1: 
- $\quad$ Saturated solution made basic with $\mathrm{NaOH}$ (anion form): $\mathrm{Abs}_{265}=1.3214$

- Saturated solution made acidic with $\mathrm{HCl}$ (protonated form): $\mathrm{Abs}_{265}=0.0946$

- $\quad$ Saturated solution brought to $\mathrm{pH} 4.84$ with $\mathrm{NaOH}$ and $\mathrm{HCl}$ (both forms): $\mathrm{Abs}_{265}=0.8716$.

The solutions were brought to equal volumes with water and the spectrum for each solution was obtained from 400 to $200 \mathrm{~nm}$ using a Cary 5000 UV-VIS spectrophotometer. The absorbance values are given at $265 \mathrm{~nm}$, which provides the greatest difference in the spectral absorptions. The $\mathrm{K}_{\mathrm{a}}$ was then determined from the following relationship:

where:

$$
\mathrm{A}_{\mathrm{M}}-\mathrm{A}_{\mathrm{A}} / \mathrm{A}_{\mathrm{B}}-\mathrm{A}_{\mathrm{M}}=\left[\mathrm{B}^{-}\right] /[\mathrm{HB}] \text { and } \mathrm{K}_{\mathrm{a}}=\left[\mathrm{H}_{3} \mathrm{O}^{+}\right]\left[\mathrm{B}^{-}\right] /[\mathrm{HB}]
$$

- $\quad \mathrm{A}_{\mathrm{M}}, \mathrm{A}_{\mathrm{A}}$ and $\mathrm{A}_{\mathrm{B}}$ are absorbance values for the Mixture, $\underline{\mathrm{A} c i d}$ and $\underline{B}$ ase solutions, respectively.

- $\quad\left[\mathrm{B}^{-}\right]$and $[\mathrm{HB}]$ are anionic and protonated forms of MTX-1.

- $\left[\mathrm{H}_{3} \mathrm{O}^{+}\right]$is the $\mathrm{H}^{+}$concentration of the mixture $(\mathrm{M})$ at $\mathrm{pH} 4.84$.

The $\mathrm{K}_{\mathrm{a}}$ calculation for MTX-1 affords:

$\mathrm{K}_{\mathrm{a}}=2.50 \times 10^{-5}, \mathrm{pKa}=4.60$

\subsubsection{Water reactivity}

The hydrolytic stability of tetrazene and MTX-1 were evaluated by UV analysis of an aqueous solution of each material over time. The samples $(\sim 0.50 \mathrm{~g}$, accurately weighed and suspended in $250 \mathrm{~mL}$ of water in a volumetric flask) were stirred at room temperature to become fully homogenized for an initial 8 hours period, after which they were stirred briefly just prior to obtaining spectra. The samples were filtered before acquisition of the UV spectra and the sample was returned to the bulk solution after sampling to maintain the concentration. The UV spectra for both tetrazene and MTX-1 are shown below in Figure 8 with the sampling times noted.

The tetrazene sample shows a rapid change in concentration over the first $8 \mathrm{~h}$ and then a bathochromic shift towards $350 \mathrm{~nm}$ (as designated by the trend line) and with increased extinction below $250 \mathrm{~nm}$, indicating that the material degrades on extended exposure to water. This would seem to confirm observations of ambient hydrolytic decomposition in tetrazene [7]. UV analysis of MTX-1 appears to indicate that there is no hydrolytic instability for that material as no shift occurs over time (vertical trend line). Interestingly, there seems to be an increase in absorbance followed by a decrease which stabilizes on extended exposure to water. This may be due to temperature variations influencing 
MTX-1 solubility in the laboratory environment; future studies may be conducted under rigorously controlled isothermal conditions. Extended storage of MTX-1 under aqueous conditions may be possible. At $\mathrm{T}=119$ days the experiment was discontinued and the solutions were filtered. Recovery of the solid tetrazene was $77 \%$ while recovery of the solid MTX-1 was $>92 \%$, as verified by FT-IR. The aqueous filtrates were evaporated under ambient conditions to give solid residues. The residue from tetrazene was determined to be primarily 5-aminoand 5-azidotetrazole by FT-IR. The filtered MTX-1 solids were recovered nearly quantitatively resulting in only a very small amount of residue $(1 \mathrm{mg})$ from the filtrate, which was not analysed but could be tetrazoles derived from small amounts of residual tetrazene starting material.
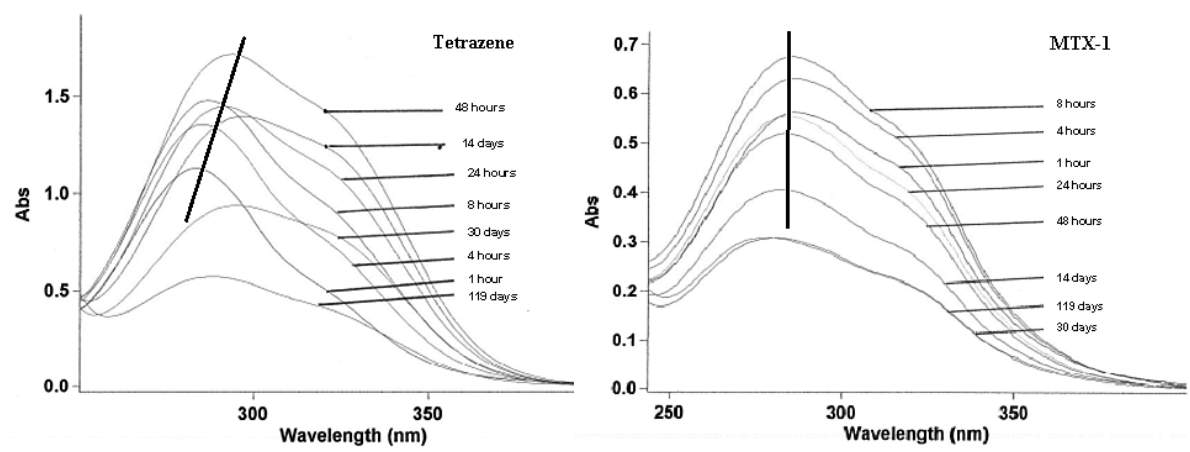

Figure 8. Exposure time $v s$. absorbance for MTX-1 and tetrazene suspensions.

\section{Explosive Handling Properties}

\subsection{Sensitivities}

The explosive handling properties for MTX-1 are shown in Table 2, along with values for tetrazene for comparison. The friction sensitivity was determined utilizing a Julius Peters small BAM tester [29] with a maximum load weight of $2075 \mathrm{~g}$. The no-fire level was determined by six successive tests with no indication of ignition. A low fire level was indicated if some level of reaction occurred in at least one of the samples at the lowest level tested above the no-fire level. The impact sensitivity testing utilized a ball drop instrument designed to meet specifications per NATO AOP-7. A chrome alloy steel ball-bearing was dropped from heights varying by $2.54 \mathrm{~cm}$ (1") onto a $0.33 \mathrm{~mm}$ thick layer of test powder on a polished steel block. Fire/no-fire results for at least 30 drops 
were determined and were analysed by a Bruceton [30] technique to give an energy value for $50 \%$ ignition. The electrostatic sensitivity data were recorded with a LEESA [31] test system utilizing methods found in MIL-STD-1751A.

Table 2. Safety data for MTX-1 and tetrazene

\begin{tabular}{|c|c|c|c|c|c|c|c|c|}
\hline \multirow[t]{2}{*}{ Sample } & \multicolumn{2}{|c|}{$\begin{array}{c}\mathrm{DSC}, 20^{\circ} \mathrm{C} / \mathrm{min} \\
{\left[{ }^{\circ} \mathrm{C}\right]}\end{array}$} & \multirow{2}{*}{$\begin{array}{c}\text { Impact } \\
\text { sensitivity } \\
{[\mathrm{J}]}\end{array}$} & \multicolumn{2}{|c|}{$\begin{array}{l}\text { Friction sensitivity } \\
\qquad[\mathrm{N}]\end{array}$} & \multicolumn{2}{|c|}{$\begin{array}{l}\text { ESD } \\
{[\mathrm{mJ}]}\end{array}$} & \multirow{2}{*}{$\begin{array}{c}\text { Weight loss at } \\
167 \mathrm{~h}, \mathrm{TGA} \\
{[\mathrm{wt} . \%]}\end{array}$} \\
\hline & onset & $\max$ & & no fire & low fire & no fire & low fire & \\
\hline & 138 & 144 & 0.021 & 1079 & & $>7.43$ & & 36.1 \\
\hline MTX-1 & 209 & 215 & 0,016 & 7.85 & 8.83 & 3.30 & 418 & 3.5 \\
\hline
\end{tabular}

\subsection{Compatibility data}

The compatibility of MTX-1 with primer constituents and a selection of primary and secondary explosives were determined utilizing DSC test methods [32, 33]. These data were generated on a TA Instruments MDSC Q2000 by blending consistent ( $\sim 50 \%$ by weight) amounts of MTX-1 and the test material and utilizing approximately $0.10-0.52 \mathrm{mg}$ of the blend in the DSC experiments. The blends were run in a hermetically sealed aluminum pan with a heating rate of $10^{\circ} \mathrm{C} \cdot \mathrm{min}^{-1}$ and the results were compared to DSC traces of the individual components run under identical conditions. It has been determined that MTX-1 is compatible with DBX-1 [34], RD-1333, KDNP [35], KDNBF, basic lead styphnate, calcium silicide, barium nitrate, antimony sulfide and PETN. It appears from the data that, as is the case with tetrazene (which forms hypersensitive silver azidotetrazole [36]), MTX-1 is not compatible with silver azide.

\section{Performance}

\subsection{Output testing}

Evaluation of the primer activity (ability to sensitize) of both MTX-1 and tetrazene was performed by mixing each with sieved basic lead styphnate (BLS, prepared per NavAir Drawing $851 \mathrm{AS} 111,-100$ sieve and dried at $82^{\circ} \mathrm{C}$ ) in a 5:95 ratio and pressing the mixture at $68.95 \mathrm{MPa}$ (10 kpsi) into standard PVU-12 brass primer cups.

A test fixture (shown in Figure 9) was designed and fabricated at Pacific Scientific Energetic Materials Company. The fixture was designed around a $1.22 \mathrm{~mm}(0.048$ ") firing pin (4) with a suitable tip radius. The primer was positioned in a base (1) such that the firing pin could rest directly on it as shown in the figure. A holding fixture (2) containing the firing pin and centering 
fixture (3), which snugly contained the firing pin, was added with the loosely fitting centering fixture moving up as the pin came into contact with the primer. A ball bearing of suitable mass could then be dropped onto the centering fixture to fire the primer reproducibly.
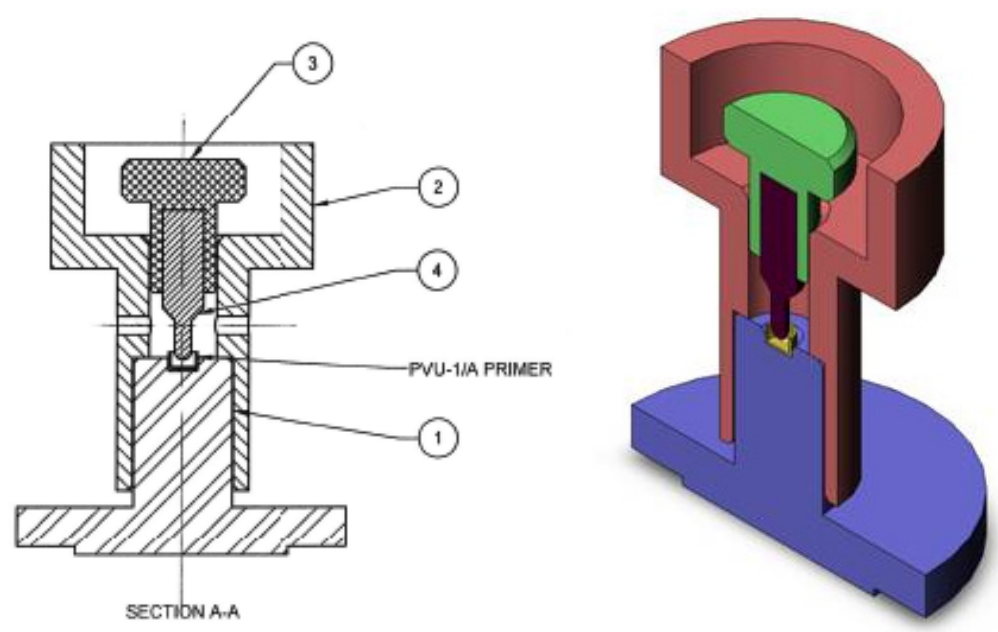

Figure 9. Test fixture for PVU-12 primer testing with section A-A (left).

Powders for testing were prepared utilizing basic lead styphnate (unmilled, \#100 sieve) as a base material and then adding 5\% of the test sensitizer and blending dry on a roller mill for $\sim 10$ minutes. Both sensitizers, MTX-1 and tetrazene, were screened through a \#40 sieve before addition to the BLS. Handling of these blended powders was minimized to prevent in homogeneity based on particle size (settling). Thirty primer cups were loaded with $21 \pm 2 \mathrm{mg}$ of BLS alone, BLS $/ 5 \%$ tetrazene and BLS $/ 5 \% \mathrm{MTX}-1$ and the powders were pressed into the primer cups with $72.57 \mathrm{~kg}(160 \mathrm{lbs})$ loading pressure and a $10 \mathrm{~s}$ dwell time. The primers (90 in total) were stored in a desiccator until tested.

A full 20 unit Neyer analysis [37] was performed on each set of primers utilizing a standard electromagnetic ball-drop primer tester fitted with the above fixture and utilizing a $94.97 \mathrm{~g}(3.35 \mathrm{oz})$ stainless steel ball. The firing pin was cleaned after every shot and examined for signs of deterioration; the pin was replaced with a new pin after every 10 shots. Initially, it was decided to fit the primer cups with a thin tape or foil closure to provide a stand-off for the firing pin, but this proved unnecessary and actually gave inconsistent results in preliminary tests so no closure was used during actual testing. The results for BLS and BLS sensitized with 5\% tetrazene and 5\% MTX-1 are shown in Table $3(\mathrm{Mu}$, mean 
drop height). These data indicate that both tetrazene and MTX-1 act as a sensitizer on BLS pressed into a primer cup with tetrazene being slightly more efficient. Note that standard deviations $(\sigma)$ were quite high for some of the data and were caused, in all cases, by one or more outlying data points which skewed the data.

Table 3. MTX-1 and tetrazene primer results

\begin{tabular}{|c|c|c|}
\hline Sample & $\begin{array}{c}\text { Mu (drop height) } \pm \sigma \\
{[\mathrm{cm}]}\end{array}$ & Energy, [mJ] \\
\hline 100\% BLS & $31.75 \pm 0$ & \\
Run 1 & $27.43 \pm 3.89$ & 295.7 \\
Run 2 & $26.04 \pm 6.71$ & 242.5 \\
Run 3 & $12.50 \pm 3.58$ & 116.3 \\
Run 1 & $13.03 \pm 3.12$ & 121.4 \\
Run 2 & $15.01 \pm 1.07$ & 139.8 \\
\hline 95\% BLS/ 5\% Tetrazene (needle) & $14.02 \pm 2.82$ & 130.6 \\
\hline Run 1 & & \\
Run 2 & $16.38 \pm 3.35$ & 152.6 \\
\hline 95\% BLS/ 5\% MTX-1 (granular) & $15.88 \pm 3.89$ & 147.9 \\
Run 1 & $14.78 \pm 4.06$ & 134.9 \\
Run 2 & \multicolumn{2}{|c|}{} \\
\hline Run 1 & & \\
\hline
\end{tabular}

Three sets of data for MTX-1, corresponding to needle, granular and mixed morphologies, are shown in Table 3. Photomicrographs (at 60X) of both needle and granular MTX-1 morphology are shown below in Figure 10 for comparison. The MTX-1 primer tests were done in chronological order and indicated that the second run in a group had a slightly higher purity level or a more consistent particle habit due to refinements in the experimental techniques. The higher purity level was confirmed by DSC analysis, and, as a result, these samples have a slightly greater ability to sensitize BLS. MTX-1 samples which formed as needles, with a morphology similar to tetrazene, have increased sensitizing ability, while samples with a smaller and more granular appearance do not sensitize to the same extent and appear more prone to agglomeration. This may create homogeneity issues and separation during blending with the BLS (or other primary explosives) which reduces the materials ability to sensitize even though the crystals are crushed during pressing. Sensitization issues related to particle morphology and size, particle hardness, hot-spot formation, and decomposition 
temperature, all of which come into play in this case, are addressed in, or in references taken from paper [7a].

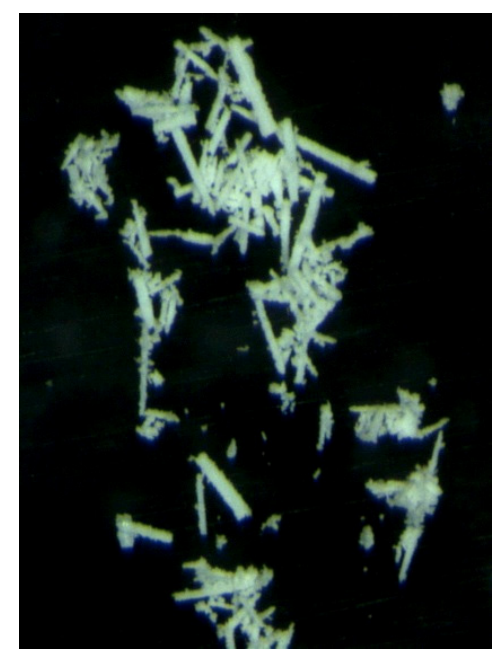

Needles, 60X

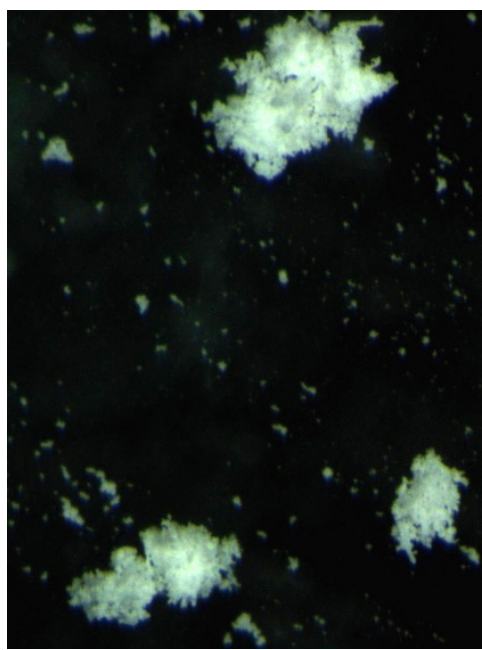

Granular, 60X

Figure 10. Photomicrographs of MTX-1 morphologies at 60X.

In general, tetrazene made by standard methods is a more efficient sensitizer of BLS compared to MTX-1 when utilized as demonstrated in PVU-12 primers. The average energy required to initiate a BLS based primer sensitized with $5 \%$ tetrazene was $\sim 118 \mathrm{~mJ}$, while those sensitized with $5 \%$ MTX-1 required $\sim 133 \mathrm{~mJ}$ or higher, depending on the morphology. Commercially available percussion and stab primers generally use $2-5 \%$ tetrazene as a sensitizing agent, and it is plausible that addition of $5-8 \%$ of MTX-1 would provide the equivalent sensitivity while affording a primer with superior thermal and hydrolytic stability.

\section{Conclusions}

Tetrazene has been shown to be both thermally and hydrolytically unstable. A potential replacement for this material, MTX-1, exhibits greatly enhanced stability and also has increased impact sensitivity compared to tetrazene. The ability of MTX-1 to sensitize BLS is slightly attenuated relative to tetrazene and seems to be dependent on the particle size and morphology, and may also be influenced by the higher decomposition temperature. MTX-1 with needle morphology provides the greatest sensitization, while the granular morphology 
provides slightly less. Mixtures of the needle and granular morphologies provide intermediate sensitization. It would appear that MTX-1 may be suitable as a replacement for tetrazene once additional investigations on particle morphology and reproducibility are completed.

\section{Acknowledgments}

The authors would like to acknowledge the contributions of Prof. Tom Klapötke (Ludwig-Maximilians University, Munich), Robert A. McCoy (PSEMC), William B. Sanborn (Raytheon), and Magdy Bichay (NSWC-IHEODTD) to this research effort. The authors also wish to acknowledge the support of Dr. Cliff Bedford and the ONR under contract awards N00014-09-M-0433, N00014-11-M-0045 and N00014-13-AF-0-0002.

\section{References}

1. Hofman K.A., Roth R., AliphatischeDiazosalze, Ber. Dt. Chem. Ges., 1910, 43, 682-688.

2. Duke J.R.C., X-Ray Crystal and Molecular Structure of Tetrazene, ('Tetracene'), $\mathrm{C}_{2} \mathrm{H}_{8} \mathrm{~N}_{10} \mathrm{O}$, J. Chem. Soc. D: Chem. Commun., 1971, (1), 2-3.

3. Kaye S.M., Encyclopedia of Explosives and Related Items (Fedoroff), vol. 8, US Army ARDEC, 1978, p. 373; Library of Congress Catalogue Card Number: 6161759.

4. Cooper P.W., Explosives Engineering, Wiley-VCH, New York, 1996, p. 323; ISBN 0-471-18686-8.

5. Bird R., The Stab Sensitizing Action of Tetrazene, Materials Research Laboratories Technical Note 362, 1975.

6. Field J., Hot Spot Ignition Mechanisms for Explosives, Acc. Chem. Res., 1992, 25(11), 489-496.

7. a) Spear R.J., Elischer P.P., Studies on Stab Initiation. Sensitization of Lead Azide by Energetic Sensitizers, Aust. J. Chem., 1982, 35(1), 1-13; b) Matyáš R., Pachman J., Primary Explosives, Springer Berlin Heidelberg, 2013, p. 191 and references therein.

8. Bird R., Power A.J., Thermal Decomposition of Tetrazene at $90{ }^{\circ} \mathrm{C}$, Materials Research Laboratories Report MRL-R-710, 1978.

9. Whelan D.J., Fitzgerald M.R., The Kinetics and Thermochemistry of the Thermal Decomposition of the Initiating Explosive, Tetrazene, DSTO Aeronautical and Maritime Research Laboratory Report DSTO-TR-0450, 1996.

10. Fronabarger J.W., Williams M.D., Sanborn W.B., Renz R., Final Report on the Investigation of the Alternatives to Lead Azide and Lead Styphnate, NSWC Contract \#N00174-03-C-0012, 30 April 2004. 
11. Ilyushin M.A., Tselinsky I.V., Shugalei I.V., Environmentally Friendly Energetic Materials for Initiation Devices, Cent. Eur. J. Energ. Mater., 2012, 9(4), 293-327.

12. a) Fronabarger J.W., Williams M.D., Hartman S., Final Report on New Materials with Enhanced Thermal Stability for Replacement of Tetrazene in Primers, ONR Contract N00014-09-M-0433, 13 September 2010; b) Fronabarger J., Williams M., Alternatives to Tetrazene, US Patent 8524 019, 2013, EP2 560 933B1, 2014 (WO 2012/003031 A2); c) Fronabarger J., Williams M., Alternatives to Tetrazene, US Patent 8632 643, 2014.

13. Lieber E., Schiff S., Henry R.A., Finnegan W.G., Acetylation and Ring Closure in Reduction of Nitro- and Nitroamino-Guanidine, J. Org. Chem., 1953, 18(2), 218-228; See also Kuzmenko V.V., Pozharskii A.F., N-Aminoazoles, in: $A d v$. Heterocycl. Chem., (Katritzky A.R.), Academic Press, San Diego, 1992, 53, 154; ISBN 978-0-12-020753-4.

14. Patinkin S.H., Horwitz J.P., Lieber E., The Structure of Tetrazene, J. Am. Chem. Soc., 1955, 77(3), 562-567.

15. Davis T.L., Chemistry of Powder and Explosives, Coll. Vol., Angriff Press, Hollywood, CA 1943, p. 449; ISBN 0913022-00-4.

16. Bruker 2010. APEX2 v2010.3-0. Bruker AXS Inc., Madison, Wisconsin, USA.

17. Bruker 2009. SAINT v7.68A. Bruker AXS Inc., Madison, Wisconsin, USA.

18. Bruker 2008. XPREP v2008/2. Bruker AXS Inc., Madison, Wisconsin, USA.

19. Bruker 2008. SADABS v2008/1, Bruker AXS Inc., Madison, Wisconsin, USA.

20. Bruker 2008. SHELXTL v2008/4. Bruker AXS Inc., Madison, Wisconsin, USA.

21. AMCP 706-177, 1971. Engineering Design Handbook: Explosives Series; Properties of Explosives of Military Interest, U.S. Army Material Command, Washington D.C. 20315.

22. Meyer R., Explosives, Verlag Chemie GmbH, Essen, 1977, p. 262.

23. ASTM E1269-05, Standard Test Method for Determining Specific Heat Capacity by DSC, ASTM International Standard, 2005.

24. MIL-STD-1751, Rev. A, Safety and Performance Tests for the Qualification of Explosives (High Explosives, Propellants and Pyrotechnics), United States Department of Defense Military Standard, 11 Dec 2001.

25. a) Kissinger H.E., Reaction Kinetics in Differential Thermal Analysis, Anal. Chem., 1957, 29(11), 1702-1706; b) Budrugeac P., Segal E., Applicability of the Kissinger Equation in Thermal Analysis, J. Therm. Anal. Calorim., 2007, 3, 703-707 and references therein.

26. Mei G.C., Pickett J.W., Molecular Modeling of Tetrazene Decomposition, Propellants Explos. Pyrotech., 1998, 23, 172-178.

27. Frank-Kamenetzkii D.A., Diffusion and Heat Transfer in Chemical Kinetics, Plenum Press, New York, 1969.

28. Ramette R., The Dissociation Quotient of Bromcresol Green, J. Chem. Educ., 1963, 40(5), 252.

29. Sućeska M., Test Methods for Explosives, Springer, New York, 1995; ISBN 9780387945552. 
30. Dixon J.W., Mood A.M., A Method for Obtaining and Analyzing Sensitivity Data, J. Am. Stat. Assoc., 1948, 43, 109-126; See also MIL-STD-1575, Method 2203.

31. Carlson R.S., Wood R.L., Development and Application of LEESA (Low Energy Electrostatic Sensitivity Apparatus), Proc. 15th Int. Pyrotechnics Seminar, Boulder, CO (USA), 1990.

32. May F.G.J., Australian Test Procedures for Determination of Compatibility and Stability of Military Explosives, J. Hazard. Mater., 1978, 2(2), 127-135.

33. a) Mazzeu M.A.C., Mattos E.C., Iha K., Studies on Compatibility of Energetic Materials by Thermal Methods, J. Aerosp. Technol. Manage., 2010, 2, 53-58; b) NATO STANAG 4147 (ed. 2), Chemical Compatibility of Ammunition Components with Explosives (Non-Nuclear Applications), 2001.

34. Fronabarger J.W., Williams M.D., Sanborn W.B., Bragg J.G., Parrish D.A., Bichay M., DBX-1 - A Lead Free Replacement for Lead Azide, Propellants Explos. Pyrotech., 2011, 36(6), 541-550.

35. Fronabarger J.W., Williams M.D., Sanborn W.B., Parrish D.A., Bichay M., KDNP - A Lead Free Replacement for Lead Styphnate, Propellants Explos. Pyrotech., 2011, 36(5), 459-470.

36. Spear R.J., Redman L.D., Bentley J.R., Sensitization of High Density Silver Azide to Stab Initiation, Materials Research Laboratories Report MRL-R-881, 1983, and references therein.

37. Neyer B.T., A D-Optimality Based Sensitivity Test, Technometrics, 1994, 36(1), 61-70. 